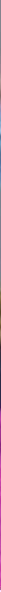

\title{
Intención artística, conservación y mutación en la obra de arte actual: una aproximación hermenéutica
}

\author{
Rosario Llamas-Pacheco
}

Resumen: La disciplina de la conservación y restauración del arte contemporáneo utiliza habitualmente el concepto de intención artística. El estudio de esta intención constituye el primer paso de cualquier intervención de conservación y restauración en una obra de arte actual y sin embargo, la significación del mismo puede variar de unas disciplinas a otras. El artículo realiza un estudio de la importancia de la figura del artista en el proceso hermenéutico de interpretación de la obra, posicionándose, al igual que otros autores, en la defensa del intencionalismo moderado como teoría que puede ayudar al conservador en el proceso de toma de decisiones. A la vez, reflexiona sobre las necesidades de la documentación de la obra de arte contemporáneo, abordando las distintas categorías ontológicas generadas por el paso del tiempo sobre la obra, y todo ello, desde la aceptación de la ruina y muerte de la obra como parte de su existencia.

Palabras clave: conservación, arte contemporáneo, intención artística, interpretación, ruina, documentación

\section{Artistic intention, conservation and mutation in the current artwork: an hermeneutical approach}

Abstract: The discipline of conservation and restoration of contemporary art usually uses the concept of artistic intention. The study of this intention is the first step in any conservation intervention in a work of contemporary art. However, the significance of this concept may vary from one discipline to another. This article presents a study of the importance of the role of the artist in the hermeneutical process of interpretation of the work, emphasizing the moderate intentionalism as a theory that can help conservators in the decision making process. At the same time, reflect on the needs of the documentation of contemporary art work, approaching the different ontological categories generated by passage of time on the work, and this, from the acceptance of ruin and death of the work as part of their existence.

Keyword: conservation, contemporary art, artistic intention, interpretation, ruin, documentation

\section{Intenção artística, conservação e mutação na obra de arte atual: uma aproximação hermenêutica}

Resumo: A disciplina da conservação e restauração de arte contemporânea utiliza habitualmente o conceito de intenção artística. $O$ estudo desta intenção constitui o primeiro passo de qualquer intervenção de conservação em uma obra de arte atual e, no entanto, a significação deste pode variar de uma disciplina para outra. $O$ artigo realiza um estudo da importância da figura do artista no processo hermenêutico de interpretação da obra, posicionando-se, como outros autores, em defesa do intencionalismo moderado como teoria que pode ajudar ao conservador no processo de tomada de decisões. Ao mesmo tempo, reflexiona sobre as necessidades da documentação da obra de arte contemporânea, abordando as distintas categorias ontológicas geradas pela passagem do tempo sobre a obra, desde a aceitação da ruína e morte da obra como parte de sua existência.

Palavras-chave: conservação, arte contemporânea, intenção artística, interpretação, ruína, documentação 


\section{Introducción}

Los conservadores de arte contemporáneo trabajan constantemente junto a los artistas, no solamente desde el plano de la conservación y restauración, también en ocasiones, en los momentos de ejecución técnica o materialización de las obras. Las obras realizadas para espacios y momentos concretos u obras site specific, necesitan de la colaboración, por otro lado muy productiva, entre los artistas, los conservadores, los historiadores y los curadores, entre otros. De este momento de colaboración se extrae información de los propios artistas en relación con la conservación de sus obras: tratamientos adecuados, materiales utilizados, significación de la materia, elementos esenciales... Esta información, deviene esencial en el caso de obras en las que la mutación no es sólo permisible, sino en ocasiones intencionada y deseada.

Por otro lado, la naturaleza de las obras, su materia constitutiva y la intención artística (primera ocasión en la que necesitamos recurrir a este concepto), requieren de una suerte de negociación entre el propietario de la obra o la institución que la expone, el artista, y el conservador; esta negociación se produce a menudo en el momento de la instalación o montaje, de modo que se evidencia una dependencia necesaria entre estos agentes artísticos (Davis y Heuman 2004: 30). La relación que se establece en este momento aporta una serie de ventajas para los conservadores aunque, por otro lado, también se producen una serie de inconvenientes. En todo caso, al trabajar junto al creador de la obra, el conservador está siempre seguro de que sus actuaciones son las adecuadas con respecto a la mencionada intención artística. Así, es necesario analizar ampliamente este concepto desde una perspectiva más próxima a la conservación de las obras de arte, aunque necesariamente arraigada en los estudios teóricos precedentes.

De cualquier modo, el trato cercano con el artista nos da idea de cómo deben utilizarse los materiales, qué significación aportan a la obra de arte desde un plano conceptual, y cómo el paso del tiempo podría afectar al estado de la materia y en consecuencia a aspectos esenciales de su significación [figura 1].

Sin embargo, también se pueden producir situaciones no tan ventajosas en la relación entre el artista y el conservador. En ocasiones el conservador corre el riesgo de sobrevalorar los deseos del artista y aceptar actuaciones que de ningún modo serían adecuadas en la restauración del arte tradicional, o que no llevaríamos a cabo en el caso de que el éste hubiera fallecido. Cabe apuntar en este momento que muchos de los tratamientos sugeridos por los propios artistas no serían aceptables para el caso de obras de tipo tradicional. Por ello, la actualización del código deontológico que rige nuestra profesión se ha hecho necesaria para el caso del arte contemporáneo. Estas cuestiones extraídas de la práctica real de la disciplina, han situado al conservador ante la necesidad de estudiar

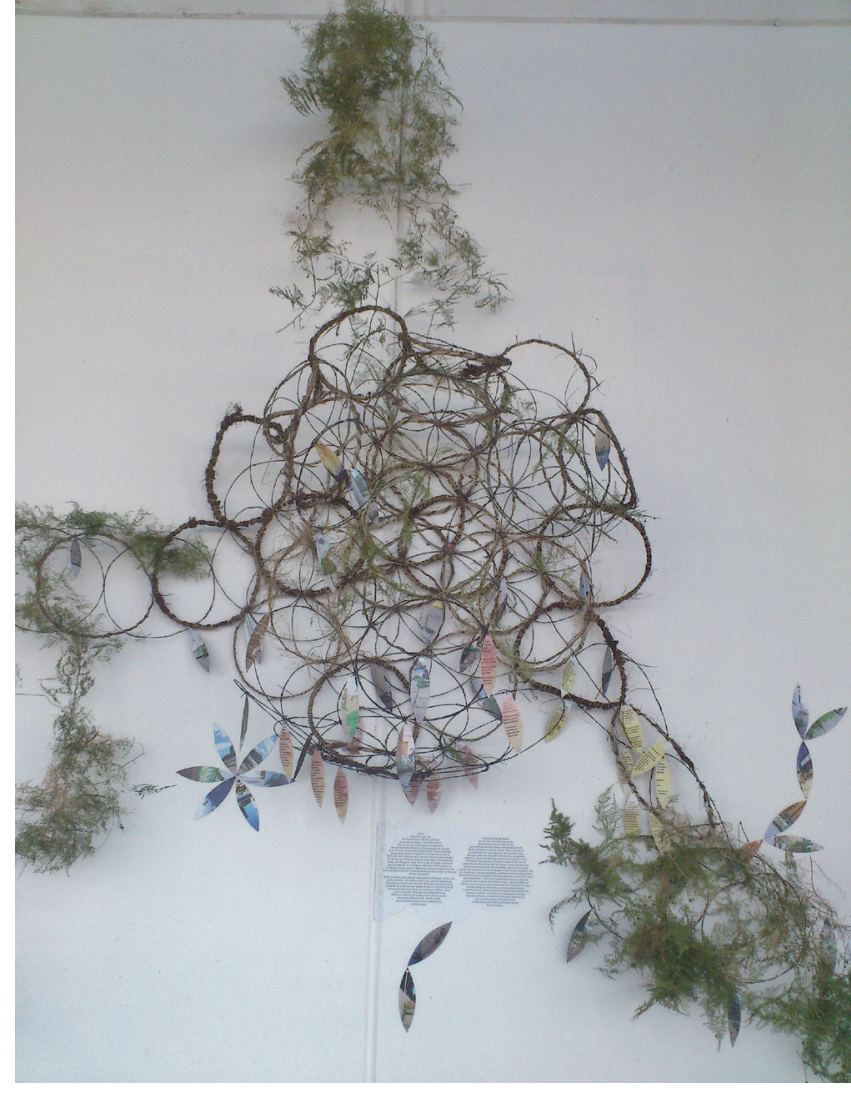

Figura 1.- Neobotánica del deseo, Moyocyani Notlinitlazotla, 2014, detalle. Obra que incluye especies botánicas como parte material.

conceptos como el de autenticidad ¿dónde reside?; aura ¿el aquí y ahora de la obra como objeto único realizado por la mano del artista determina la autenticidad?; la reposición o sustitución de la materia de una obra, ¿afecta a cuestiones esenciales?; o la importancia de la mano del artista en el proceso de restauración, ¿puede el restaurador realizar las mimas intervenciones, atrevidas, que haría el artista?

Por otro lado, en ocasiones, el conservador adopta el papel de mero asistente del artista, un asistente gratuito que le ayuda a materializar sus instalaciones artísticas [figura 2]. Con todo, y aun conociendo los principios que podrían desaconsejarlo, desde aquí defendemos la postura de numerosos autores que reivindican la necesidad de interpretación y entendimiento de la obra con la ayuda del propio artista. En este sentido debemos abordar la entrevista al artista desde un punto de vista hermenéutico, es decir, como una herramienta que tomada con cautela puede ayudar a aprehender la significación de la obra.

En cualquier caso, el contacto directo con los artistas desde el mundo de la conservación y restauración nos permite aportar una visión novedosa a la cuestión de la intención artística, una visión fundamentada en la praxis, pero que no puede obviar los estudios teóricos anteriores en relación con dicha intención. 


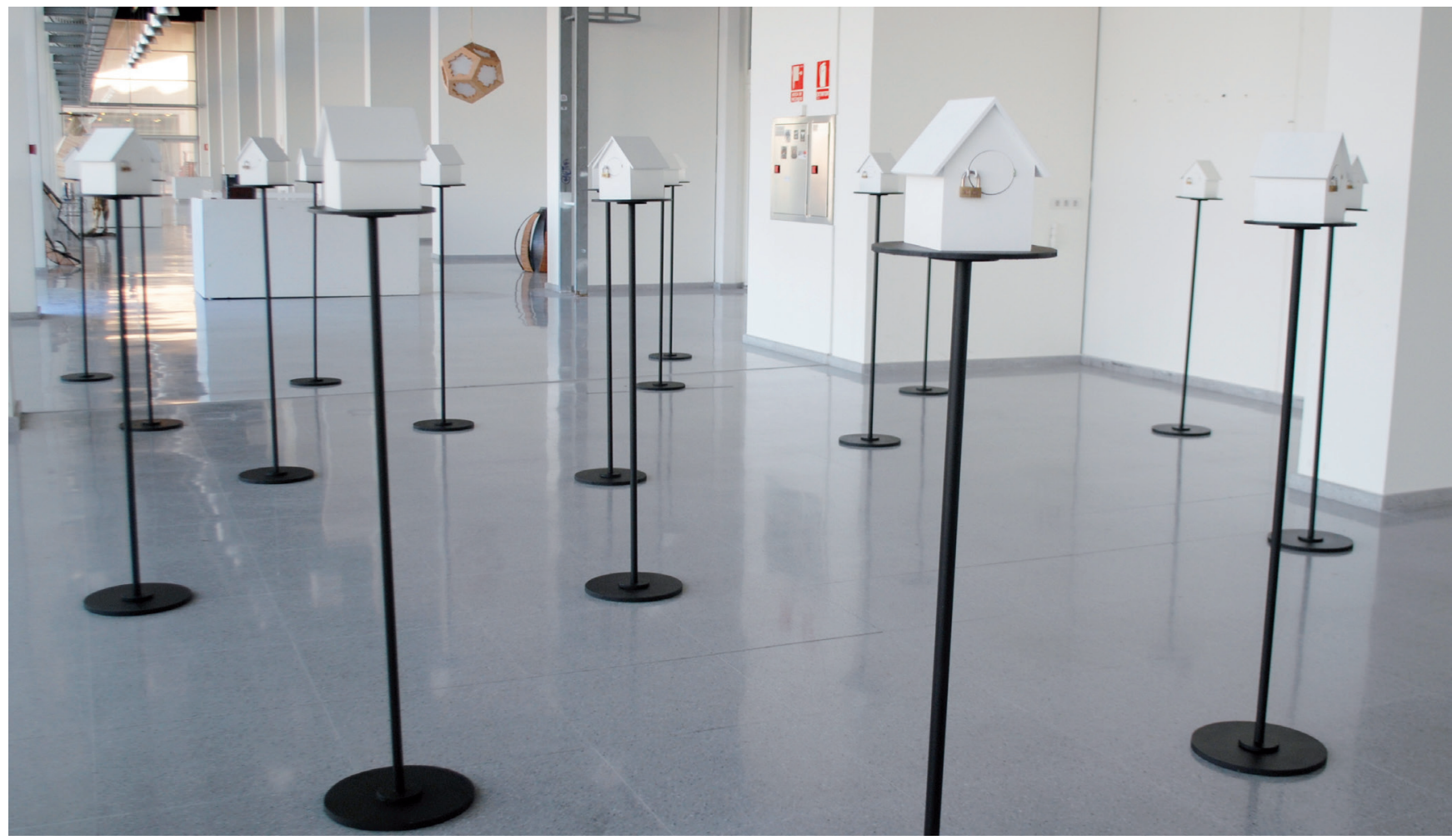

Figura 2.- Algo falla, Adrián Castañeda, 2016. El artista siente la necesidad de ayudar en el proceso de interpretación de la obra, por lo que durante la exposición, junto a la misma, coloca el siguiente texto explicativo: "La obra nos invita a introducirnos en una laberíntica red de casas convertidas en jaulas y golpearnos, cerradura tras cerradura, con una narración de la realidad convertida en diecinueve números que reflejan la cifra de ejecuciones hipotecarias de las diferentes comunidades autónomas que coexisten en España".

En este sentido, podemos señalar algunas cuestiones que observadas desde un plano pragmático, nos sitúan en el ámbito de la conservación del arte contemporáneo ante la disyuntiva de respetar el mencionado código deontológico o seguir los dictados de la voluntad artística. Así, en determinadas ocasiones, no es posible seguir los criterios de intervención fundamentales para la conservación del arte tradicional, como la mínima intervención o el respeto por la materia prístina, puesto que la voluntad artística no lo permite. Por ello, cabe preguntarse en qué consiste la obra realmente y qué importancia tiene la materia para cada caso. Hoy en día podemos encontrar obras en las que el artista obliga al conservador a reponer la materia sistemáticamente, obras en las que la mutación y decadencia de la materia son esperadas, u obras carentes de materia entre exposición y exposición. Es en este punto en el que el conservador ha debido asumir un cambio de paradigma, ya asentado, que le permite, desde el respeto a la obra en primer término, abordar la difícil tarea de manejarse entre la voluntad del artista, la evolución de los criterios de intervención necesaria, el entendimiento de dónde radica la autenticidad de la obra, la ética profesional, la presión del mercado del arte, las cuestiones legales y las posibilidades técnicas, entre otros. Y todo ello tras haber entendido el carácter ontológico de la obra que pretende conservary desde el convencimiento de que no es posible trasmitir correctamente al futuro aquello que se desconoce.

\section{¿Son las obras de arte objetos independientes de sus respectivos creadores? La cuestión de la intención artística y la conservación}

Son numerosos los autores que han estudiado el concepto de intencionalidad artística. Ya hacia la mitad del siglo XX se generó una controversia alrededor del mismo, estableciéndose una disputa entre conservadores e historiadores del arte que centró el foco en la necesidad de concretar el papel que la ciencia y la historia del arte, debían desempeñar en el proceso de interpretación de la intención artística. Ante la afirmación de que el objetivo de la conservación del arte era presentar la obra para su entendimiento con respecto a la intención artística, conservadores e historiadores asumieron posturas diferentes (Dykstra 1996: 197-218). En la controversia ocurrida en la National Gallery alrededor de los años cincuenta en relación con el concepto de intención artística y la limpieza de las obras, fue definida la idea de que debía seguirse la intención artística como un principio de la conservación.

Paralelamente empezó a estudiarse el concepto de intención artística desde un punto de vista filosófico. Tras la publicación del artículo "La Falacia Internacional" (Wimsatt y Beardsley 1954) que no otorgaba a los artistas un papel esencial en la crítica del arte, se produjo un intenso debate entre historiadores, filósofos y críticos de arte. Este artículo argumentó que el término "intención" 
era demasiado ambiguo y de difícil evaluación y aplicación para ser tenido en cuenta. En este sentido son de gran importancia los estudios de Mieke Bal sobre los conceptos, sobre el tránsito que realizan de una disciplina a otra y sobre cómo evoluciona su significación:

“... los conceptos no están fijos, sino que viajan entre disciplinas- entre estudiosos y estudiosas individuales, entre periodos históricos y entre comunidades académicas geográficamente dispersas. Entre las disciplinas, el significado, alcance y valor operativo de los conceptos difiere. Estos procesos de diferenciación, deben ser evaluados antes, durante y después de cada "viaje" (Bal Mieke 2002: 37).

En cualquier caso, el término intención artística es hoy en día utilizado continuamente en el ámbito de la conservación y debe ser analizado y estudiado en relación con el arte contemporáneo y en relación con los creadores artísticos [figura 3 y 4]. Y empezando por el principio, Pérez Carreño (2001: 151-167) apunta que para crear una obra de arte es necesaria una intencionalidad artística previa. Según esta autora "al hacer de la intencionalidad un rasgo esencial de lo artístico, se elimina la posibilidad de hablar de obra de arte en sentido literal sobre un trabajo bien hecho o de un buen golpe de revés o de una

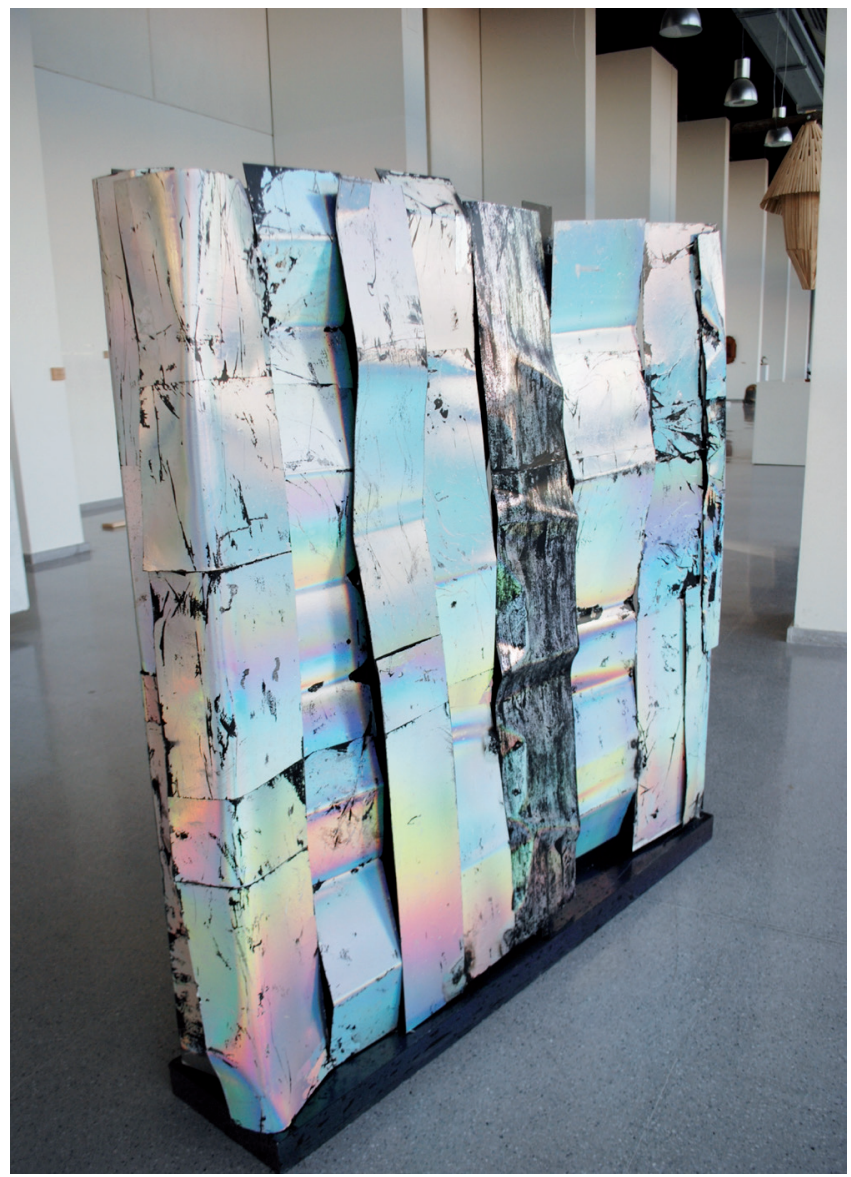

Figura 3.- Holografhic Wall, Miguel Aparicio, 2016

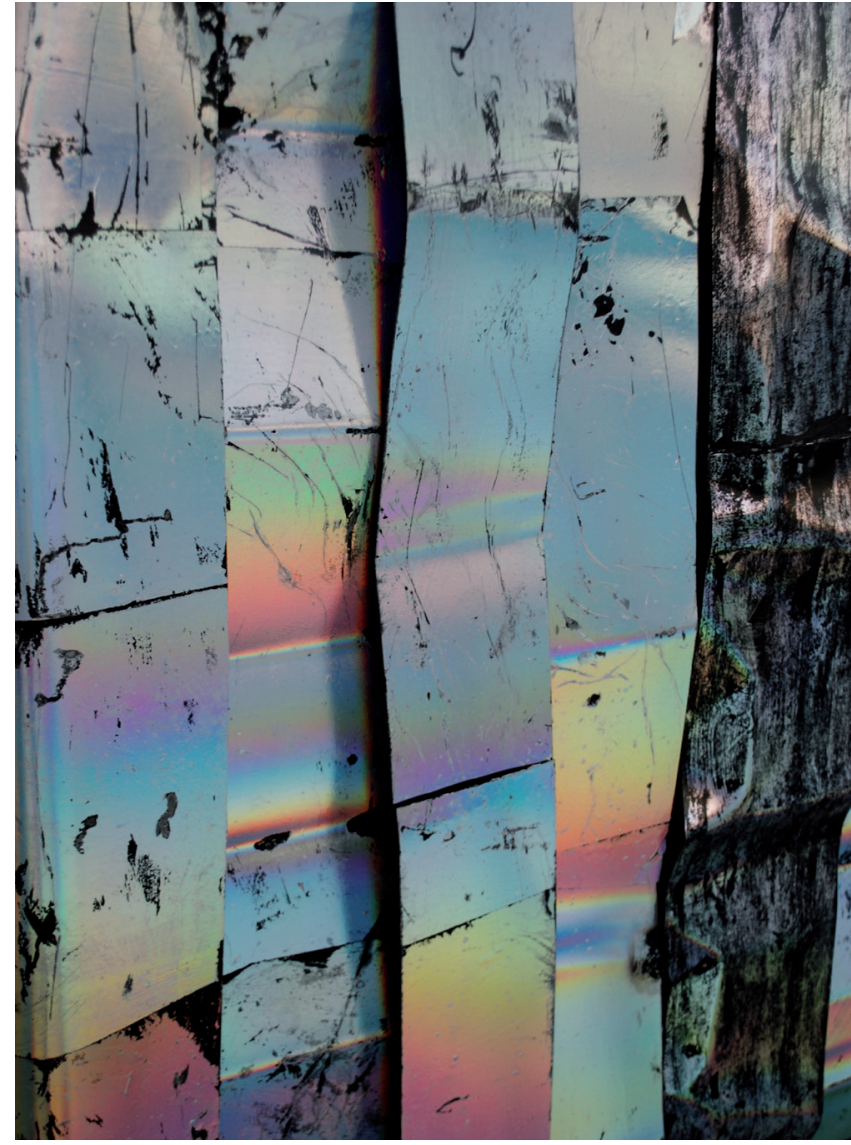

Figura 4.- Holografhic Wall, Miguel Aparicio, 2016, Detalle

bella puesta de sol." Así pues, para crear una obra de arte sería necesaria una intención artística previa.

Sin embargo, la intención artística no siempre está disponible, y según autores ni siquiera es deseable o importante. El término, por otro lado, presenta numerosas variaciones de significado (Dykstra 1996: 205-212). Además, la intención artística no es inmutable, o lo que los artistas nos pueden explicar con el paso del tiempo, puede ser olvidada, evolucionar, o verse presionada por elementos externos como el mercado del arte. La interpretación de la intención artística es una tarea que compete a varias disciplinas, pero de facto, el conservador de arte contemporáneo se ve envuelto en la necesidad de entendimiento de esa intención cuando lo que pretende es conservar la obra y transmitirla al futuro.

Sixto J. Castro (2008: 139-159) analiza las posturas intencionalista y anti-intencionalista en relación con la interpretación artística, así como las nuevas posturas intermedias del intencionalismo hipotético y el intencionalismo moderado, y ello con la intención de presentar su punto de vista. Este autor se decanta por el intencionalismo moderado como la mejor solución provisional para la interpretación de la obra de arte ya que, según apunta, "buena parte de la riqueza expresiva estética de una obra deriva de su apertura interpretativa", de este modo se pregunta sobre el papel de la intención del autor en la constitución del significado de la obra. 
Dentro del ámbito de la conservación y restauración del arte contemporáneo es imprescindible conocer los valores esenciales de la obra, pues es necesario interpretarla y analizarla para poder preservarla. Tradicionalmente, en este sentido, la figura del artista ha tenido un papel fundamental en los procesos de documentación, tanto del plano material como del plano conceptual de las mismas. Pero ante esta ayuda habitual, que forma parte de los procesos de toma de decisiones, cabe preguntarse hasta qué punto debe tenerse en cuenta la participación del artista en la constitución del significado de la obra.

En relación con la intención artística, autores como Hirsch (1976: 51) sugieren que la intención del autor está en el propio objeto, en la propia obra, determinada por la voluntad del autor. Así, habría una única interpretación correcta de la obra, incluida en la misma obra: la obra significaría lo que el autor tiene la intención que signifique.

La teoría intencionalista insiste a su vez en que dar más relevancia a las intenciones del autor puede enriquecer nuestra interpretación de las obras, y defiende que las intenciones autoriales son importantes para la interpretación del significado de las mismas. Sin embargo, en contraposición a esta teoría, la corriente antiintencionalista afirma que las consideraciones sobre las intenciones del autor son irrelevantes para el propósito de la interpretación.

Además cabría reflexionar, en relación con la intención artística, sobre la evidencia interna y la evidencia externa, categorías presentes en el objeto artístico. La evidencia interna se descubre por el conocimiento del lenguaje plástico, por la semántica, por el conocimiento de la cultura: se trataría de un elemento de carácter público, reconocible para un público adecuado. Por el contrario, la evidencia externa de la obra es privada, no se deduce automáticamente, se construye a partir de informaciones obtenidas a través de cartas, entrevistas, conversaciones... Así, las obras de arte se descubrirían a través de estas evidencias, las cuales en ocasiones, se solapan.

Dykstra (1996: 215) defiende que la intención artística debe entenderse únicamente como la explicación de los aspectos estilísticos individuales de una obra de arte, específicamente en asuntos de materia y técnica, los cuales distinguen a cada estilo artístico. Para este autor, la intención artística puede ser investigada y aplicada en la conservación del arte en términos de utilidad, con la intención de distinguir las características e individualidades de determinados artistas y sus obras, pero desde una visión técnica. Sin embargo, nos parece ésta una visión un poco limitada de este concepto, aun entendiendo su postura, la cual revela la confusión generalizada en la interpretación del término, pues la complejidad de situaciones ante las que el conservador de arte contemporáneo puede enfrentarse, le obligan a ir más allá en el análisis de las obras.
En cualquier caso, la praxis de la conservación y restauración hace necesario el estudio de cuestiones esenciales como la reedición de las obras, por impuesta; la reposición de elementos, por necesaria; la búsqueda del lugar en que radica la autenticidad de la obra, por la imposibilidad de mantener inmutable la materia prístina; o el concepto de ruina, por la incapacidad de la materia de cumplir la función estética deseada. Es la propia praxis de la conservación del arte actual y la naturaleza variada y poco convencional de las obras, las que sitúan al restaurador/conservador ante la necesidad de resolver problemas nunca antes estudiados en el arte.

Otro punto de vista interesante a tener en cuenta en el ámbito de la conservación de las obras de arte contemporáneo, y en relación con la postura, esta vez de los anti-intencionalistas, es el que sostiene que el significado de una obra cambia incluso para el autor. Es éste un aspecto que hemos podido comprobar a lo largo de las numerosas entrevistas realizadas a los artistas. Es posible que el mismo artista, en un momento inicial de creación de su obra pretenda una interpretación para la misma, y que esta interpretación varíe con el paso de los años; estaríamos ante una teoría de la mutabilidad semántica. Este hecho es real para el caso del arte contemporáneo, y esto porque el artista es una persona, y como tal, que olvida y evoluciona.

En el caso del lenguaje escrito, como apunta Sixto J. Castro (2008: 143) el significado de un texto, aunque sea olvidado por su autor, puede ser interpretado, pues el autor utilizó una secuencia de signos particulares que representan algo en concreto, de este modo, utilizaríamos el significado autorial como principio normativo de interpretación. Sin embargo, en el caso del arte contemporáneo, la adjudicación del significado al signo no es tan evidente [figura 5], y en ocasiones, podría verse afectada la conservación de la obra ante el olvido o la mutación de la significación. No hay que olvidar que en este proceso hermenéutico se produce una relación entre significado y persona y en este punto se introduce un elemento variable.

Y por otro lado, la obra de arte es sobre algo, como apunta Danto y comenta Carreño (2001: 166-167), la obra de arte lo es sólo en función de una interpretación, ahora bien, esta interpretación sólo es posible para quien ya sepa manejarse en el mundo del arte, es decir, para quien posea un concepto previo de arte. Y llevado este punto al mundo de la conservación y restauración ilustra la necesidad de interpretación necesaria de la obra antes de poder proponer unas directrices correctas para su conservación.

Otra cuestión apuntada por Hirch (1976) es que a veces, el autor no sabe lo que quiere decir (estaríamos hablando de un argumento que señala la ignorancia autorial), y en otras, el significado no es accesible para el espectador, o no es alcanzable con toda certeza. Existe en el arte contemporáneo la posibilidad de que el artista indique que la obra significa lo que se quiera que signifique; es este un hecho bastante habitual que nos sitúa ante la teoría del significado público y la irrelevancia autorial para agilizar la identificación del significado de una obra. 


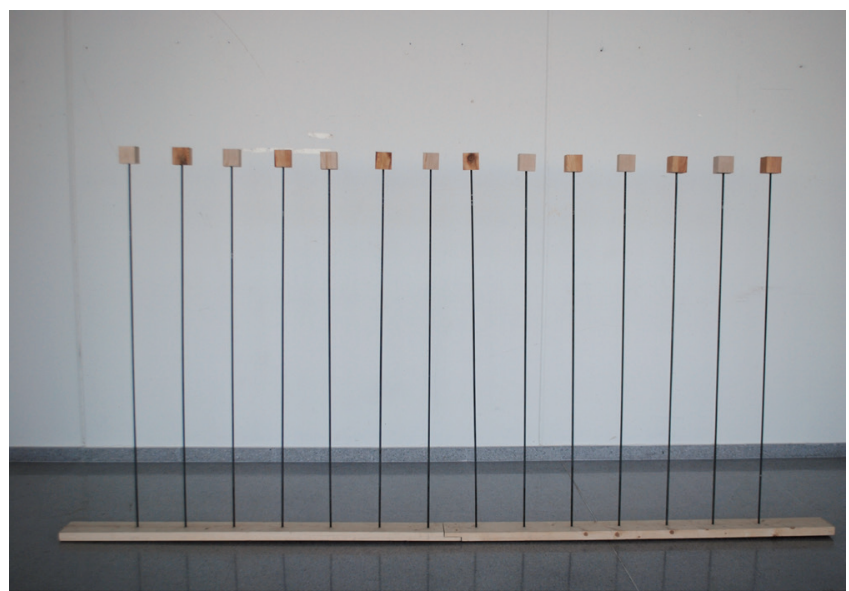

Figura 5.- Diálogo fallido, Judith Marínez, 2016.

En cualquier caso, el proceso de interpretación no resulta sencillo. El Historicismo radical es una teoría que apunta que las obras cambian su significado a lo largo de la historia, de modo que el crítico debería extraer el nuevo significado actual, dado que los significados particulares quedarían obsoletos al volverse inaccesibles. Por otro lado, los historicistas también defienden la intraducibilidad de los significados entre las diversas épocas.

Otro autor que aborda la interpretación de la obra de arte es Richard Wollheim. Para Wollheim la crítica consiste en reconstruir el proceso creativo, el cual termina en la obra de arte misma, de modo que este proceso adquiere una importancia capital (Wollheim 1995: 404-414). Según esta teoría, una vez que la obra ha sido recuperada, gracias a la reconstrucción del proceso creativo, estaría dispuesta para ser comprendida.

\section{Las entrevistas con los artistas}

Es indiscutible el valor de las entrevistas personales a los artistas contemporáneos, entrevistas que vienen realizándose sistemáticamente como punto inicial de los procesos de intervención, porque, para determinar el significado de una obra de arte, primero hay que determinar cuáles son las propiedades de la obra de arte que portan el significado y esto se realiza analizando el proceso creativo y necesariamente a los propios artistas. ¿Sobre qué deberíamos preguntar a los artistas en las entrevistas? ¿Dónde radican los aspectos esenciales de las obras, aquellos que las dotan de carácter artístico? ¿Qué significa la materia para el autor? ¿Cómo se espera que se comporte para que su condición no afecte a la significación de la obra?

El proceso creativo es un fenómeno amplio, incluye las vicisitudes a las que están sometidas las intenciones del artista. Estas vicisitudes en ocasiones son intencionales pero a veces casuales, se fundamentan en las múltiples creencias, convencionesy modos dela producción artística sobre los que el artista forma sus intenciones. El proceso creativo incluye la interpretación por parte del artista de las normas estéticas del momento, las innovaciones del medio, las reglas, las imágenes del mundo que posee el artista, los sistemas de simbolización, la tradición... por ello, el conocimiento de este proceso deviene esencial en los procesos de documentación de las obras de arte, y esto, porque ayuda a conocer la naturaleza ontológica de la obra. No es posible negar que en este proceso, el papel que juega el propio artista sea extremadamente útil.

Y por otro lado ¿cómo podemos estar seguros como apunta Jerrold Levinson (1996) de que la intención hipotéticamente construida coincide con la intención real que tuvo el autor? Cabría apuntar que gracias a las entrevistas, pero como dijimos anteriormente, también los artistas olvidan.

Por otro lado, Noël Carroll considera que la intención autorial debe figurar en la interpretación de la obra, este autor propone el "intencionalismo real moderado", teoría que niega sin embargo, que la intención autorial determina por completo el significado (Castro 2008: 153154). Porque como apunta Castro "la interpretación del arte no puede labrarse simplemente como aplicación de convenciones, sino esforzándose por reconocer las intenciones de los artistas de modo semejante a como tratamos de buscar las intenciones de los interlocutores en el habla cotidiana".

En este sentido, para poder interpretar las obras de arte contemporáneo debemos conocer el contexto cultural en que se producen, el trasfondo semántico que las envuelve, el género, el entorno..., y para ello, de nuevo, es esencial el contacto directo con los artistas y el registro de las entrevistas, hecho que ya desde hace años se viene realizando. Es esencial en este sentido el esfuerzo realizado por el grupo INCCA (International Network for Conservation of Contemporary Art) quien tradicionalmente viene recopilando entrevistas a artistas. De este modo, y tal como permite el intencionalismo real moderado, el intérprete puede acceder a las declaraciones privadas del artista, es decir, a las entrevistas, las cuales pueden ser un elemento más de ayuda en el proceso de interpretación de las obras.

\section{La necesidad de conservar la memoria: entre el aura y la mutación}

María Rodríguez García (2012: 259-266) señala el punto de vista de Ortega y Gasset en la obra Meditación de la técnica de 1933. Ortega y Gasset define los actos técnicos como aquellos que se encargan de satisfacer las necesidades de los hombres, pero que además, transforman las circunstancias que provocan esas necesidades, para que el hombre no sólo esté, sino que esté bien. La condición técnica del hombre es la que le lleva a concebir la vida no como un simple estar en ella, sino como un estar bien. Como conservadores debemos reflexionar sobre este 
hecho, ya que podríamos estar trasladando esta idea a las propias obras, haciendo que éstas no solo estén, sino que estén bien como apunta esta autora. $Y$ a esta interesante reflexión podríamos añadir una cuestión ¿somos los conservadores capaces de refrenar nuestro impulso de conservar la obra ante todo, para asumir que la obra puede desaparecer como efecto de su propia naturaleza?

La cuestión es que en algunas ocasiones el artista, maravillosamente, nos sitúa ante situaciones con las que no habíamos contado, como la reedición o la sustitución necesaria de la materia, y ello siendo parte de la intención artística. Los conservadores hemos asumido que nuestro papel es vehicular: no forma parte de la obra sino en la medida en que el artista decida que pueda hacerlo. Y sí, los conservadores ya hemos entendido que algunas obras de arte contemporáneo, por su naturaleza material, sufrirán una evolución, una mutación y una transformación de la apariencia prístina que irremediablemente las conducirá hasta el estado de ruina, dada la imposibilidad de la materia constitutiva de transmitir su carga semántica. Y sin embargo, y esto es lo que hace de la conservación del arte contemporáneo una disciplina apasionante, los propios artistas se han encargado de rebajar nuestros miedos, al enfrentarnos ante la necesidad de sustituir la materia de algunas obras, ante la necesidad de reeditarlas intermitentemente y por ende, ante la necesidad de concretar dónde residen los aspectos esenciales de las mismas, por ser éstos el motivo de conservación. Traer al presente la dimensión creativa del artista puede formar parte de nuestro quehacer, pero no es algo que haya propuesto el conservador, es algo que la propia creación artística, trasgresora e incontrolable, ha decidido.

Así, al estudiar las relaciones institucionales entre el conservador, el museo y la obra, tal como apunta Martore (2014), las posibles prácticas de conservación no pueden ser rígidas, sino que han de ser flexibles, pues el museo recibe el objeto artístico no importa lo inusual que sea. Del mismo modo, el conservador se convierte en un agente llamado a interaccionar con el objeto artístico, siendo capaz de manejar la inestabilidad de la obra y los múltiples significados posibles, ampliando necesariamente la naturaleza de sus intervenciones.

Y por otro lado, y simultáneamente (de nuevo lo complejo y apasionante del arte contemporáneo), al hablar del paso del tiempo podemos enfrentarnos a varias situaciones. Ya no es para el conservador de arte contemporáneo un conflicto, el hecho de asumir que una obra ha muerto y presenta ante nosotros su materia arruinada. Somos capaces de dejar transcurrir el tiempo, y de observar cómo su efecto, irreversible, afecta en ocasiones a cuestiones esenciales, conduciendo a las obras inexorablemente hacia ese estado de ruina, estado asumido en algunas ocasiones por los propios autores.

La modernidad es la época de la reproductibilidad técnica, como indica Walter Benjamin (2003). Este autor analiza los cambios técnicos producidos a principios del siglo XX, los cuales, necesariamente, le obligan a reflexionar sobre la autenticidad de los objetos artísticos, sobre el aura, y sobre la originalidad de las obras. Hoy en día los artistas realizan proyectos que luego son materializados por otras personas. ¿Dónde queda la importancia de la mano del artista? Para Benjamin, el aura es fruto del aquí y ahora, estaría relacionada con la existencia singular e irrepetible de la obra, la autenticidad estaría vinculada al aura y ligada al ser único, pero ¿qué ocurre en el caso de los artistas contemporáneos que no materializan personalmente sus obras, y que las reeditan intermitentemente como en el caso de las instalaciones? No podemos insistir en que la reinstalación de una obra en un museo no es auténtica porque parte de su materia original haya tenido que ser sustituida. La reinstalación será auténtica, aunque su parte material no sea la que sirvió para concretar la obra inicialmente.

Y sin embargo, sí debemos preguntarnos sobre cómo el artista ha conseguido librarse de la tiranía del efecto del tiempo sobre la materia. Artistas como Sol Lewitt han conseguido situar sus obras en un eterno presente, despojándolas de la materia que decae y situando ante nosotros una nueva categoría ontológica.

Y por otro lado ¿cuál es el verdadero estado auténtico de una obra? ciertamente, cabe preguntarse hasta qué punto es posible conocer con exactitud ese estado inicial. Al respecto, ya hemos asumido que los conservadores de arte contemporáneo no pretendemos congelar las obras en un determinado estado, sino guiar y atender a su evolución a través del tiempo, determinando qué rasgos son esenciales en las mismas y por tanto, el objeto de nuestra conservación; y determinando qué elementos pueden ser sustituidos por no ser esenciales para la obra. $Y$ esto desde el conocimiento de que también debemos asumir la muerte de la obra de arte como parte de su existencia, una existencia trágica al igual que la del ser humano (Rodríguez 2012: 264).

\section{Documentación}

Recientemente hemos asistido a una necesidad cada vez mayor de conservar la memoria histórica (Nora 19841992; Huyssen 2002), "[...] En relación con el nuevo boom por conservar la memoria acaecido en los últimos años, cabe insistir en que el restaurador, para el caso del arte contemporáneo, no pretende en ocasiones conservar el recuerdo de la obra, sino la obra misma" (LLAMASPACHECO, 2015: 229).

La necesidad antropológica de legar nuestro patrimonio cultural al futuro nos afecta de varios modos. Por un lado, existe la voluntad de documentar las obras con la intención de trasmitirlas, al menos como parte que fueron en su momento de nuestro acervo cultural, (muchas obras contemporáneas presentan un carácter 
efímero o han sido realizadas con materiales que se degradan rápidamente y no se conservarán en su plenitud estética) [figura 6]. Este tipo de categoría situará ante nosotros la materia arruinada, cierto, pero merecedora igualmente de ser conservada por ser portadora de otro tipo de valores importantes (sociales, culturales, icónicos...).

Por otro lado, el arte conceptual, las instalaciones o el performance, son ejecutados para un tiempo y un espacio determinados. También el arte de los nuevos medios utiliza elementos tecnológicos que devienen obsoletos en un corto periodo de tiempo. Puede ocurrir en este caso que la obra sólo deba existir en una ocasión, y que de esta acción se generen los restos materiales que deberán ser preservados. La documentación del acto artístico puede por sí misma convertirse en la materia a conservar.

Pero en relación con la reposición y la materialización intermitente de las obras conceptuales o las instalaciones, la documentación adquiere una nueva dimensión. La documentación en este caso deviene fundamental; una documentación que debe atender al conocimiento tácito, pero también a los aspectos intangibles de las creaciones. En este sentido, recientemente han sido revisados los criterios que determinaban qué era considerado

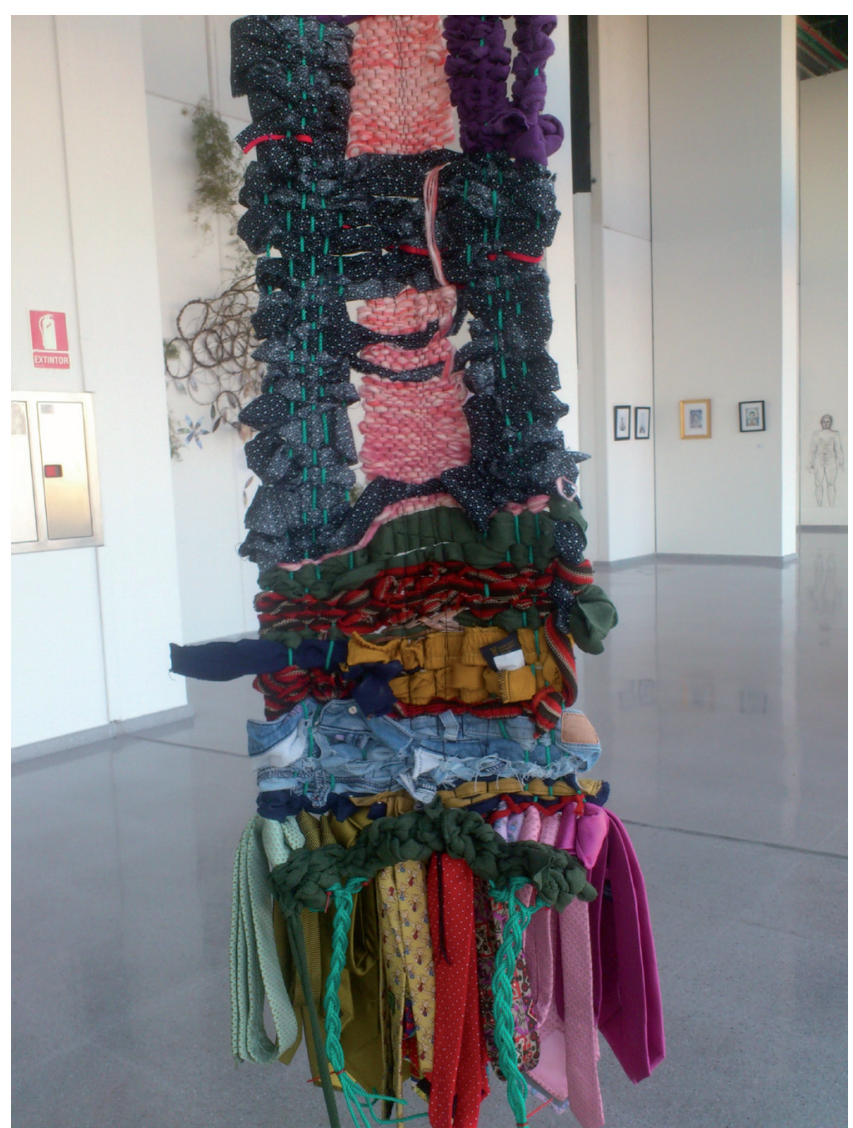

Figura 6.- Dejar ir para construir, Mitzi Jimena Azpeitia Espinosa, 2014, detalle. Ropa reciclada como material base de ejecución de la obra. patrimonio cultural, criterios que tradicionalmente hacían hincapié en los valores históricos y artísticos de las obras. Actualmente ha sido necesario revisar estos criterios para incluir otros valores como el valor de identidad y de capacidad del objeto para interactuar con la memoria. Esta revisión ha hecho posible reconocer el patrimonio inmaterial, el cual había sido ignorado hasta el momento, con la intención de ser protegido y conservado igualmente, y se ha puesto de relieve la importancia de los aspectos inmateriales en diversos tipos de manifestaciones culturales (Vecco 2010: 321324).

Continuando con el tema de la documentación del arte contemporáneo, es evidente que aparece una situación novedosa propuesta por los propios artistas. Para el caso de Sol Lewitt mencionado anteriormente, sus ayudantes o asistentes comparten el conocimiento de la obra alrededor del mundo. Aunque las instrucciones de Lewitt incluyen indicaciones sobre cómo llevar las obras al muro, la traslación de este conocimiento requiere de conocimiento tácito no explícito (Hummelen y Scholte 2004: 208-212). Así, los asistentes indican cómo deben aplicarse los colores y materializarse las obras, pero para este caso en concreto, la documentación debería hacerse de manera extremadamente minuciosa, determinando cómo deben aplicarse los colores, con qué medios, etc, pues la obra llegará al futuro fielmente si este proceso de documentación tiene éxito.

Es muy importante señalar que en este caso la documentación de la obra no es entendida como un proceso de conservación de la memoria histórica. Hemos analizado cómo Lewitt consigue llevar sus obras a un eterno presente, pues su materialización periódica se insertará en sucesivos momentos históricos futuros, y en todos ellos la materia mínima necesaria será nueva. Estaríamos hablando de documentar para transmitir la propia obra, no para conocer el estado prístino de la misma o su evolución a lo largo del tiempo.

\section{Conclusiones}

¿Puedeelconservador/restauradordeartecontemporáneo preservar y hacer posible la transmisión de un bien cultural al futuro si no lo conoce? ¿Es la interpretación de la obra una necesidad inherente del proceso de conservación/ restauración? ¿Qué importancia tiene la figura del artista en este proceso de interpretación de las obras y hasta qué punto debería influir en la conservación de las mismas?

La obra de arte es un complejo ente cultural dotado de variados valores que le hacen merecedora de ser conservada. Sin embargo, no es posible conservar y legar al futuro aquello que no se conoce. En este sentido, la interpretación de la significación tiene en el propio artista una gran ayuda, tal y como apunta el intencionalismo moderado, y puede, junto con otros factores, ser tenida 
en cuenta en el proceso de toma de decisiones necesario para conservar la obra.

La intención artística y su relación con el paso del tiempo presentan numerosas vertientes. Podemos encontrarnos ante variadas posibilidades: de un lado, el artista puede introducir la mutación y decadencia como parte del proceso creativo, previendo incluso la ruina y la muerte de la obra, sin que el conservador debiera interferir en ese proceso. De otro lado, el artista puede pretender, como en el caso de Juan Genovés, que la materia permanezca viva todo el tiempo que sea posible, "[...] confío en que el cuadro esté vivo dentro de muchos años aunque la tela haya amarilleado un poquito. A mí no me gustaría que envejecieran (las obras). Lo que sí me importa es que lo que pinte encima de la tela se mantenga vivo y con fuerza..." (LLAMASPACHECO, 2015: 224)

A la vez, podemos encontrar el caso en que la materia de la obra se degrade irremediablemente sin que sea parte de la intención artística, llegando al estado de ruina prematura y no deseada. Y ampliando las posibilidades, también podemos encontrarnos con obras situadas en un continuo presente, dada su materialización intermitente, como en el caso de los Wall Paintings de Sol Lewitt.

Las situaciones son variadas, y afectan al estatus de las creaciones. La necesidad de reflexión teórica previa a los procesos de intervención es evidente, pues el conservador de arte contemporáneo se sitúa ante situaciones no imaginadas por teóricos precedentes. En este sentido, el acercamiento a otras disciplinas como la antropología, la filosofía, o la psicología pueden ser de gran ayuda.

\section{Agradecimientos}

Este trabajo se enmarca dentro del proyecto con referencia: HAR 2013-41010-P concedido por el Ministerio de Economía y Competitividad. Secretaría de Estado de investigación, Desarrollo e Innovación, dentro del Programa Estatal de Investigación Científica y Técnica de Excelencia (2014-2017).

\section{Bibliografía}

BAL M. (2009): Conceptos viajeros en las Humanidades: una guía de viaje, Murcia: Cendeac.

BENJAMIN W. 82003): La obra de arte en la época de su reproductibilidad técnica, México D.F., Itaca.

CASTRO SIXTO J. (2008): "El papel de la intención en la interpretación artística", Revista de Filosofía, Vol. 33 Núm. 1: 139-159.
DAVIS, L. y HEUMAN, J. (2004): “Meaning matters: Collaborating with contemporary artist", en Studies in Conservation, 49: sup2, 30-33.

DYKSTRA, STEVEN W. (1996): "The artist's intention and the intentional fallacy in fine arts conservation", en JAIC 35:197218.

HIRSCH, E.D. (1976): The Aims of Interpretation, Chicago, University of Chicago Press.

HUMMELEN I. y SCHOLTE T. (2004): "Sharing Knowledge for the conservation of contemporary art: changing roles in a museum without walls" en Studies in Conservation, 49 sup2: 208-212.

HUYSSEN A. (2002): Presentes: los medios de comunicación, la política, la amnesia, en Global-local: democracia, memoria, identidades, Montevideo: Trilce, 217-237.

JERROLD, L. (1996): "Intention and interpretation in Literature", en J. Levinson, The Pleasures of Aesthetics, Ithaca, N.Y. Cornell University Press.

LLAMAS-PACHECO, R (2015): “El artista contemporáneo ante la transformación de su obra. El paso del tiempo y su efecto sobre la significación de la materia" en Arte, Individuo y Sociedad 27 (2), 211-228.

MARTORE, P. (2014): "Parasites of the Glory" en CeROArt [en línea], 9/2014, puesto en línea el 22 de enero de 2014, consultado el 2 de febrero de 2016. URL: http://ceroart.revues. org/3768.

NORA P. (dir.), (1984-1992): Les lieux de mémoire. Paris: Gallimard.

PÉREZ CARREÑO, F. (2001): "Institución-arte e intencionalidad artísitca" en Enrahonar 32/33, pp. 151-167

WIMSATT, W.K. y M. BEARDSLEY (1954): "The Intentional Fallacy", recogido en The Verbal Icon: Studies in the Meaning of Poetry, Lexington: U. of Kentucky Press.

RODRÍGUEZ GARCÍA, M. (2012): “Conservación y metafísica realizada", en Actas de las 13 Jornadas de Conservación de Arte Contemporáneo, Madrid: Museo Nacional Centro de Arte Reina Sofía, 259-266.

VECCO M. (2010): "A definition of cultural heritage" en Journal of cultural heritage, 11: 321-324.

WOLLHEIM R.: "Criticism as Retrieval" en A. Neill y A. Ridley (eds.), Philosophy of Art: Readings Ancient and Modern, Boston, McGraw-Hill, pp. 404-414 


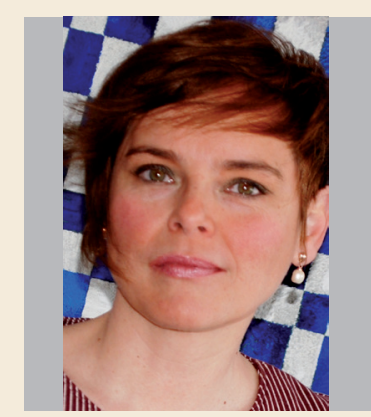

\section{Rosario Llamas-Pacheco}

rllamas@crbc.upv.es

Universidad Politécnica de Valencia

Es doctora en Bellas Artes y Profesora Titular del Departamento de Conservación y Restauración de Bienes Culturales. Es miembro del Instituto Universitario de Restauración del Patrimonio de la Universidad Politécnica de Valencia. Ha impartido clase en diversas universidades, tanto en grado, como en máster y doctorado. Ha dirigido más de veinte tesis de máster y trabajos de investigación, así como varias tesis doctorales. En el ámbito de la gestión universitaria, ha sido directora académica del Máster en Conservación y Restauración de Bienes Culturales de la Universidad Politécnica de Valencia. Cuenta con una gran cantidad de publicaciones, tanto de tipo docente como investigador. Ha publicado en las revistas nacionales e internacionales más prestigiosas, y ha participado en gran cantidad de eventos relativos a la conservación y restauración del arte contemporáneo. Ha sido la investigadora responsable de diferentes proyectos de investigación. En la actualidad es la investigadora principal de un proyecto del Ministerio de Economía y Competitividad, dentro del Programa Estatal de Investigación Científica y Técnica de Excelencia. 